\title{
Evaluation of the Quality of the Setting up of Early Mother-Born Interactions
}

\author{
G. Chtabou, Khaoula Mammad*, M. Chkirate, K. Karjouh, A. O. T. Ahami \\ Unit of Clinical and Cognitive Neuroscience and Nutritional Health, Department of Biology, Faculty of Science, Kenitra, Morocco \\ Email: *khaoula.mammad@gmail.com
}

How to cite this paper: Chtabou, G., Mammad, K., Chkirate, M., Karjouh, K. and Ahami, A.O.T. (2019) Evaluation of the Quality of the Setting up of Early Mother-Born Interactions. Open Journal of Medical Psychology, 8, 66-77.

https://doi.org/10.4236/ojmp.2019.84007

Received: April 2, 2019

Accepted: September 6, 2019

Published: September 9, 2019

Copyright (c) 2019 by author(s) and Scientific Research Publishing Inc. This work is licensed under the Creative Commons Attribution International License (CC BY 4.0).

http://creativecommons.org/licenses/by/4.0/

\begin{abstract}
The maternity process that has unfolded throughout the pregnancy, undergoes a turning point that occurs most of the time during the stay in diaper: place for installation of early mother-born interactions. The objective of the study is the evaluation of the quality of the establishment of early motherborn interactions as well as the effect of maternal feeling disruption on these interactions. It is a prospective study, focused on a total of 102 maternalNew-born dyads, in the unit of maternity series, at Rabat Children's Hospital, University Hospital of Ibn Sina. It was based on a scale and an evaluation grid: the Mother-to-Infant Bonding Scale MIBQ and an evaluation grid of early mother-child interactions. The results showed that the age of the youth who is dominated at $60 \%$ (between 21 and 30 years), and that the primiparity was at $54 \%$ and $51 \%$ healthy; the correlation analysis between MIBQ and the grid shows that there is a significant correlation of average size with the emotional stability of the mother $(\mathrm{p}=0.014<0.05)$, the quality of the attachment of the baby as his mother at the moment breastfeeding $(\mathrm{p}=0.011<0.05)$ and the quality of the observed family context $(p=0.017<0.05)$. The installation of the mother-child relationship therefore depends on maternal capacities to recognize her place as a mother and to recognize the needs of their child, but it also depends on the child's ability to show signs of attachment, his feelings of discomfort and pleasure.
\end{abstract}

\section{Keywords}

Maternity, Mother, New-Born, Interaction, MIBQ

\section{Introduction}

For a long time, the baby has often been considered as a passive being, influenced by his environment and, in the first place, by his mother [1]. Early assessment of mother-infant relationship is priority goal in maternity, because of 
its importance for the child's psycho-emotional and somatic development and for the prevention of abuse [2] [3] [4] [5]. As well as reducing of maternal and newborn hospital stay in industrialized countries in recent decades [6], this task is becoming more complex and encourages the development of practical tools to help teams perform this assessment early [5].

Disruption of the mother-baby interaction is often the only and first indication of difficulties and problems in the baby's constitution. Their evaluation has therefore become a common practice for both clinicians (most of the services that host babies use interaction grids) and for researchers [7]. For the codified evaluation of the mother-child relationship should, theoretically, include an evaluation of observable behaviours or mother-child interactions (video-filmed) but this type of evaluation is not compatible with everyday practices [5].

Immediately after giving birth, most mothers feel a special affection for their children and automatically start breastfeeding and keeping them clean. However, in some cases the mother does not experience these feelings, or even perhaps an aversion to the child [8]. As a result, she is unable to connect with the child or provide adequate maternal care, as suggested risk factors include: being unmarried or unemployed [9], social desirability and attachment of adults [10], having caesarean section [11], the mother's personality [12], social support during pregnancy [13] [14], and the mother's perceptions of how from which she was raised in her childhood [14]. In addition, suggested risk factors for children include night crying [15] and, in cultures with a preference for boys, being a girl [16].

Although mother-born early interactions remain a very affordable subject at the international level and in behavioral psychoanalysis, it does not seem to be a subject of national interest, as the small number of articles listed in Moroccan literature shows, probably for reasons technical and institutional, because the range of behaviors of the newborn is limited and we can not explain to him a stain by the language: to be done one will rely on these sensory-motor capacity like sucking, watching, crying, or touching [17].

The pregnancy process that occurs during pregnancy occurs most often during the stay in diapers where mother-baby bonding is established through early interactions, in moments so full of sense and affect, it has been interesting to use this time to conduct this study and evaluate the quality of the implementation of early mother-new born interactions. The objective of the study is the evaluation of the quality of the establishment of early mother-new born interactions as well as the effect of maternal feeling disruption on these interactions.

\section{Material and Method}

\subsection{Participants}

A total of 102 maternal-Newborn dyads, in the hospital of mternity and reproductive health the ORANGERS of the hospital university Ibn Sina at Rabat. The criteria for inclusion: Every woman had given birth in the maternity ward and 
subsequently stayed in the service of the layer suites with her newborn baby in a normal state. Criteria for exclusion: Mothers whose babies were transferred to other services for medical reasons; Mothers who gave birth to a stillbirth or who lost their baby after birth; Mothers who gave birth to premature babies; and finally mothers who refuse to participate in the study.

\subsection{Assessements}

\section{MIBQ: Mother Infant Banding Questionnaire}

It was scored twice, once to cover how the mother felt immediately after childbirth (Time 1) and once how she had felt since then (Time 2). The MIBQ consists of 8 statements describing an emotional response, such as "loving" or "disappointed", which are rated on a 4-point Likert scale from very much (score $=0$ ) to not at all (score $=3$ ). Five items describe negative emotional responses and are reverse scored. Low scores denote good bonding. Scores can range from 0 to 24 [18].

Otherwise, Marjorie (2008) [19] defines at 2 the threshold for the diagnosis of difficulty of the mother-child interaction with a sensitivity of 0.9 and a specificity of 0.8 ( $90 \%$ of chances of being positive when one is a carrier of $80 \%$ to be negative when one is not carrying any disruption). In addition, it evaluates the risk of having a disruption to $40.9 \%$ knowing that the test is positive, that is to say when the score obtained is greater than 2 and $98.1 \%$ to be healthy, knowing that the test is negative (score less than 2). Due to the very narrow score distribution (between 0 and 6 while the possible rating is 0 to 24).

\section{Evaluation Grid for Early Interactions Mother-Child}

To study early mother-new interactions, it has been found useful to find a way that can: Evaluate interactions in its bidirectional aspect; Be adapted to the very early times of the interaction; And the handover must be fast to be able to be conducted in the classic operating conditions of the service of diapers at maternity series, at Rabat University Hospital Center (UHC) of Ibn Sina.

The choice fell on a grid of evaluation of the early interactions, developed from another grid of observation which was elaborated by the team of perinatality of Dr. V. Lemaitre (2011), with the UHC of Lille.

The grid wants to synthesize the knowledge brought by the work carried out in perinatality on the understanding of the baby, his mother and especially the mother-child interactions in the first days of life.

The items in the grid are based on work on baby's early skills, attachment theory, post-natal depression, and knowledge of early interactions, and 13 items were selected:

- The identification' needs of the baby by his mother (eat, sleep...)

- The understanding of the behavior of the baby by his mother

- The quality of Handing

- The quality of the Holding

- The appearance of the looks between the mother-baby dyad

- The mother's ability to calm her baby 
- Interpretation of crying

- Shared pleasure at the time of feeding between the mother and the baby

- The mother's availability and emotional security in the face of her baby

- Emotional stability in the mother

- Emotional and emotional communication between the mother-child dyad

- The quality of the baby's attachment to his mother when breastfeeding.

- Quality of the family context observed (will she be alone with her child) The reliability analysis shows Cronbach's alpha equal to $0.837>0.6$, which indicates that our evaluation grid for early mother-child interactions is reliable, or we can say that the internal consistency of the items in the observation grid is acceptable.

\subsection{Methodology}

It was a prospective study that took place 3 months: between April and June 2013 in the hospital of maternity and reproductive health the ORANGERS of the University Hospital Center Ibn Sina at Rabat. Within 24 hours to 48 hours postpartum, and after the mother's consent, the MIBQ will be distributed to him within 15 to 30 minutes. If unable to do so for pathological reasons or illiteracy, make sure to enter the information on the questionnaire. The evaluation grid, for its part, is completed based on the observation of the different reactions between the mother-child dyads.

\subsection{Statistical Analysis}

This phase of the survey included the following steps: Entering data into Excel, Coding items from the questionnaires and the grid, and statistical analysis of the data, which was done using the IBM SPSS Statistics software, version 21, to calculate mean and standard deviations (SD), and to make correlations between different parameters.

\section{Results}

\subsection{The Representation of the Population According to the Neurocognitive Evaluation}

\section{According to the MIBQ test. evaluation of child mother interactions.}

It is found that $51 \%$ of the studied dyads show interaction problems, although $49 \%$ are healthy (Figure 1 ).

\section{$>$ According to the items in the evaluation grid for early mother-baby in- teractions:}

The item 1 of the evaluation grid shows that half of the mothers who have been tested, have the ability to identify the need of their babies (51\%), also with the item 2 mothers studied have a middle capacity in understanding the behaviour of their babies (52\%). Item 3 shows that $48 \%$ have a middle quality. Issue 4 shows a middle dominant holding quality by (44\%), Issue 5 means that it's really the best thing ever (58.9\%). The ability to calm their mothers' babies is consid- 
ered middle in most cases (53\%). The interpretation of crying seems very difficult for the majority of mothers, noting that only $(3.90 \%)$ is interpreted very well by crying.

Furthermore, a large majority of women provide emotional availability and security for their children (92\% split between middle and perfect). And also shows that half of the mothers studied $(70.60 \%)$ are emotionally stable. The majority of mothers approve of poor communication with their babies or even absent in some cases $(6 \%)$. And that $(57,8 \%)$ of the babies studied approved a good attachment, at the time of feeding. Finally, a striking absence of the family context in $(75 \%)$ of the cases studied (Table 1$)$.

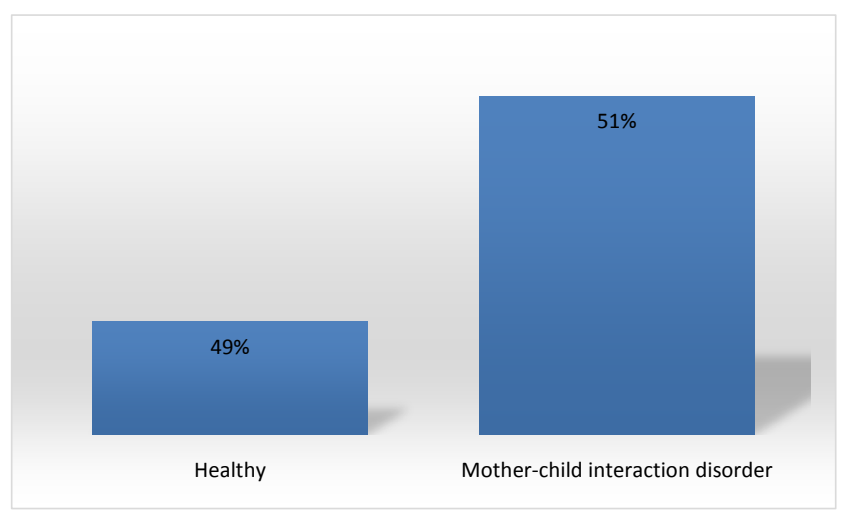

Figure 1. Distribution of the population according to the MIBQ test.

Table 1. According to the items in the evaluation grid for early mother-baby interactions:

\begin{tabular}{|c|c|c|c|c|c|c|}
\hline items & Perfect & Very good & Good & Middle & $\mathrm{Bad}$ & Absent \\
\hline $\begin{array}{l}\text { 1) The identification' needs of the baby } \\
\text { by his mother (eat, sleep ...) }\end{array}$ & $0 \%$ & $5.9 \%$ & $26.5 \%$ & $51 \%$ & $16.7 \%$ & $0 \%$ \\
\hline $\begin{array}{l}\text { 2) The understanding of the behavior of } \\
\text { the baby by his mother }\end{array}$ & $0 \%$ & $4.9 \%$ & $25.5 \%$ & $52 \%$ & $17.6 \%$ & $0 \%$ \\
\hline 3) The quality of Handing & $0 \%$ & $6.9 \%$ & $33.3 \%$ & $48 \%$ & $11.8 \%$ & $0 \%$ \\
\hline 4) The quality of the Holding & $0 \%$ & $5.9 \%$ & $36.3 \%$ & $44.1 \%$ & $12.7 \%$ & $1 \%$ \\
\hline $\begin{array}{l}\text { 5) The appearance of the looks between } \\
\text { the mother-baby dyad }\end{array}$ & $0 \%$ & $11.8 \%$ & $43.1 \%$ & $34.3 \%$ & $10.8 \%$ & $0 \%$ \\
\hline 6) The mother's ability to calm her baby & $0 \%$ & $3.9 \%$ & $38.2 \%$ & $52.9 \%$ & $4.9 \%$ & $0 \%$ \\
\hline 7) Interpretation of crying & $0 \%$ & $3.9 \%$ & $17.6 \%$ & $64.7 \%$ & $13.7 \%$ & $0 \%$ \\
\hline $\begin{array}{l}\text { 8) Shared pleasure at the time of feeding } \\
\text { between the mother and the baby }\end{array}$ & $2 \%$ & $6.9 \%$ & $23.5 \%$ & $53.9 \%$ & $11.8 \%$ & $2 \%$ \\
\hline $\begin{array}{l}\text { 9) The mother's availability and emotional } \\
\text { security in the face of her baby }\end{array}$ & $1 \%$ & $18.6 \%$ & $32.4 \%$ & $40.2 \%$ & $7.8 \%$ & $0 \%$ \\
\hline 10) Emotional stability in the mother & $0 \%$ & $16.7 \%$ & $53.9 \%$ & $22.5 \%$ & $6.9 \%$ & $0 \%$ \\
\hline $\begin{array}{l}\text { 11) Emotional and emotional } \\
\text { communication between the mother-child } \\
\text { dyad }\end{array}$ & $0 \%$ & $3.9 \%$ & $16.7 \%$ & $40.2 \%$ & $33.3 \%$ & $5.9 \%$ \\
\hline $\begin{array}{l}\text { 12) The quality of the baby's attachment } \\
\text { to his mother when breastfeeding. }\end{array}$ & $0 \%$ & $18.6 \%$ & $39.2 \%$ & $36.3 \%$ & $5.9 \%$ & $0 \%$ \\
\hline $\begin{array}{l}\text { 13) Quality of the family context observed } \\
\text { (will she be alone with her child) }\end{array}$ & $0 \%$ & $4.9 \%$ & $7.8 \%$ & $6.9 \%$ & $5.9 \%$ & $74.5 \%$ \\
\hline
\end{tabular}




\subsection{Factor Analysis of the Observation Grid}

\subsubsection{The Principal Component Analysis Matrix}

The matrix of components after rotation Varimax, determines 3 components (Table 2):

- Component 1: included items $1 ; 2 ; 3 ; 4 ; 6 ; 7$.

- Component 2: included items $5 ; 8 ; 9 ; 10 ; 12$.

- Component 3: items 13.

\subsubsection{The Factorial Map}

The factorial map shows that the items of the two components 1 and 2 are scattered in the same positive plane $(\mathrm{X}, \mathrm{Y})$ whereas the item 13 of the component 3 which represents the $Z$ axis is very far away.

Referring to the grid, we find that these components evaluate different dimensions: component 1 evaluates the behavioural aspect of early interactions; component 2 evaluates the affective aspect of early interactions, and component 3 revealed that item 13 (Figure 2).

\subsubsection{The Principal Component Analysis Matrix after Item 13 Elimination}

The post-rotation PCR matrix Varimax revealed two components: component 1 and component 2 (Table 3 ).

\subsubsection{The Factorial Map after Elimination of Item 13}

According to the new factorial map after item 13 has been eliminated, there is a consistent dispersion of the items between them (Figure 3 ).

Table 2. The principal components analysis matrix.

\begin{tabular}{cccc}
\hline & \multicolumn{3}{c}{ Matrix of components after rotation ${ }^{\mathrm{a}}$} \\
& 1 & Components & \\
\cline { 2 - 4 } & 0.731 & 2 & 3 \\
\hline item 1 & 0.807 & 0.300 & 0.170 \\
item 2 & 0.755 & 0.258 & -0.084 \\
item 3 & 0.810 & 0.179 & 0.292 \\
item 4 & 0.202 & 0.106 & 0.176 \\
item 5 & 0.713 & 0.601 & 0.033 \\
item 6 & 0.582 & 0.139 & -0.246 \\
item 7 & 0.105 & 0.442 & -0.130 \\
item 8 & 0.255 & 0.804 & -0.020 \\
item 9 & 0.141 & 0.731 & 0.008 \\
item 10 & 0.175 & 0.686 & 0.067 \\
item 11 & 0.436 & 0.496 & 0.425 \\
item 12 & 0.009 & 0.514 & -0.252 \\
item 13 & -0.025 & 0.848
\end{tabular}

Extraction method: Principal component analysis. Rotation method: Varimax with Kaiser normalization. a The rotation converged in 4 iterations. 
Table 3. Principal components analysis matrix after elimination.

\begin{tabular}{ccc}
\hline & \multicolumn{2}{c}{ Matrix of components after rotation $^{\mathrm{a}}$} \\
\cline { 2 - 3 } & 1 & Components \\
\hline item 1 & 0.731 & 2 \\
item 2 & 0.801 & 0.314 \\
item 3 & 0.764 & 0.261 \\
item 4 & 0.816 & 0.194 \\
item 5 & 0.198 & 0.118 \\
item 6 & 0.703 & 0.604 \\
item 7 & 0.573 & 0.136 \\
item 8 & 0.097 & 0.442 \\
item 9 & 0.249 & 0.803 \\
item 10 & 0.137 & 0.733 \\
item 11 & 0.185 & 0.690 \\
item 12 & 0.424 & 0.511 \\
\hline
\end{tabular}

Extraction method: Principal component analysis. Rotation method: Varimax with Kaiser normalization. a. The rotation converged in 3 iterations.

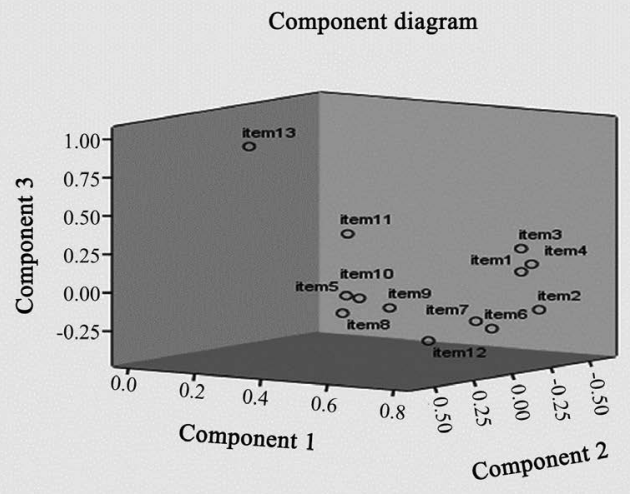

Figure 2. The factorial map of the grid components.

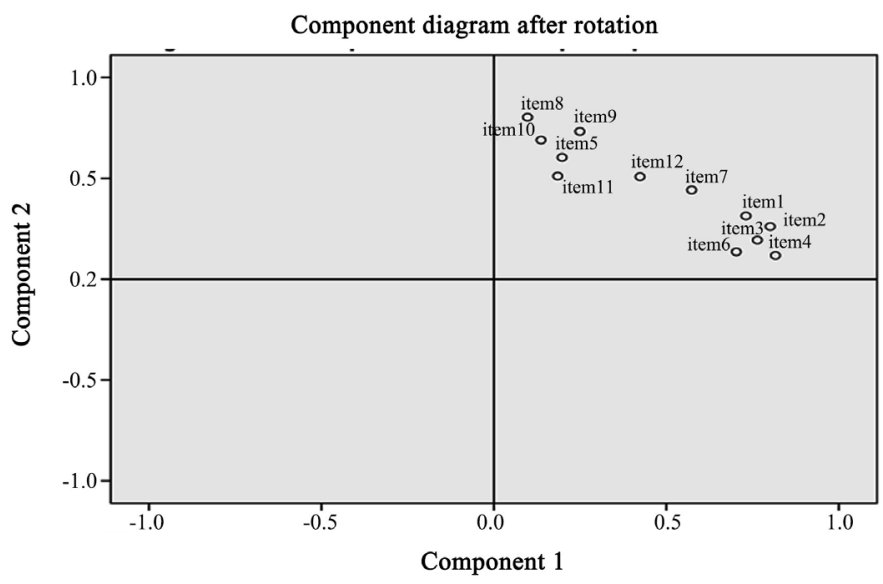

Figure 3. The new factorial map of two components of the grid. 


\subsection{Correlational Analysis}

\section{Correlation between the MIBQ and the Items of the Grid}

Correlational analysis between the items of grid and the MIBQ test revealed that there is a correlation between some items in the grid $(10,12)$ and the MIBQ score.

Item $10 *$ Emotional stability in the mother

Item $12 *$ The quality of the baby's attachment to his mother when breastfeeding.

Our result shows a positive correlation $(\mathrm{p}<0.01, \mathrm{r}=0.243)$ between emotional stability in the mother and the MIBQ test, which assesses mother-child early interactions, and positive correlation $(\mathrm{p}<0.01 \mathrm{r}=2.51)$ between the quality of the attachment of the baby to his mother at the time of breastfeeding and the MIBQ test (Table 4).

\section{Discussion}

In the light of the results obtained from the analysis, 102 women were included in this study. The target population, given its specificity, was a well-defined population: women of childbearing age, with a young age dominance between 21 and 30 years, well over half $(60.78 \%)$. On the side of parity we notice that primiparous women, have also exceeded half (54.90\%).

MIBQ test scores revealed that $51 \%$ of the women studied had bonding disruption with their babies in the first hours after birth, although just $49 \%$ managed to make healthy connections with their babies (Figure 1). Some estimate the prevalence of mothers with a neonatal relationship disorder, all grades, between $6 \%$ and $7 \%$, two weeks after delivery [20], while a severe disorder with rejection of the child would affect $0.5 \%$ to $1 \%$ of mothers [21].

Moreover, we distributed the MIBQ 24 to 48 hours after delivery, with mothers reporting more positive feelings about their newborn between the second and fourth day postpartum than immediately after birth [22]. Self-questionnaires are also subject to social desirability [23]: mothers are aware that some responses are "better perceived" than others. Their emotional security contributes to their ability to confide or not to negative emotions and also to perceive them [24], which could explain the percentage $51 \%$ in our sample (Figure 1).

Our objective was to identify the effect of disturbances of maternal feeling on early interactions rather than to identify the associated pathologies that could affect the link because the temporal constraint of habitual hospitalization

Table 4. Pearson correlation between item $10 \& 12$ and the MIBQ test:

\begin{tabular}{ccc}
\hline & Moyenne \pm écart type & significatin \\
\hline Item $10^{*}$ & $3.2 \pm 0.797$ & $\mathrm{P}=0.014<0.05$ \\
MIBQ & $1.51 \pm 0.502$ & $\mathrm{r}=0.243$ \\
Item $12^{*}$ & $3.29 \pm 0.839$ & $\mathrm{P}=0.011<0.05$ \\
MIBQ & $1.51 \pm 0.502$ & $\mathrm{r}=2.51$ \\
\hline
\end{tabular}


in maternity rarely allows the diagnosis of pathology of mother-child link requiring symptom duration at least greater than 1 week [21], however the authors of the MIBQ validation study [18] argue, in fact, that the very narrow score distribution suggests that the questionnaire is probably better at detecting the most "abnormal" responses than subtle variations of the normal.

In a study [25] found a significant correlation between MIBQ scores in the first weeks of postpartum, scores at 9 weeks, at 16 weeks and at 1 year, which encourages a prevention and management of difficulties in the establishment of the mother-child relationship, as soon as possible. In addition, another Japanese study [12] defines a two-factor structure of the tool (lack of affection, \& an anger and rejection). Other Japanese authors have proposed a validation of the Japanese version of the MIBQ in 10 items [26].

According to the figure (Figure 2) where the factorial map shows that the items of the two components 1 and 2 are scattered in the same positive plane (X, $\mathrm{Y}$ ) whereas the item 13 (the quality of the observed family context) of the component 3 which represents the $Z$ axis is very far away which had almost the same response by all subjects, that makes it non-discriminatory, lead us to eliminate it. Furthermore, in Table 1 we find that in item 13: 75\% of moms were alone in front of their babies who only enjoy a few minutes to a few hours visits from their families, $75 \%$ of women provides care and take charge of them and their babies alone (Table 1). This means that the disruption of maternal feeling could have a negative impact on the establishment of the mother-born bond, hence the need to set up an adequate management program to prevent difficulties and guide the relationship between the dyad.

Otherwise, after elimination of item 13 (Figure $3 \&$ Table 3) the correlation analysis between the MIBQ and the grid showed a significant relationship between the items: 10,12 which are respectively: the emotional stability of the mother, the quality of the baby's attachment to her mother at the moment breastfeeding, (Table 4). Item 10 of the Early Interaction Rating Matrix reveals that mothers experience high quality emotional stability, up to $70.60 \%$, with respect to their baby. Almost the same thing happens with item 12: $57.8 \%$ of babies have a good attachment to breastfeeding (Table 1).

In his study, Bienfait, found the existence of $13 \%$ of difficulties of motherchild relationship [5]. His study made it possible to determine the diagnosis threshold of mother-child link disruption from a MIBQ score equal to or greater than 2, but strongly advising the passage of an interview as a means of ruling out false positives. According to her, this interview should allow the identification of some points that seem important to address with mothers (experience of pregnancy, childbirth, environment, social support, relationship with dad, and that the MIBQ score alone can not be used to diagnose mother-child interaction disruption. It is the interviews that will make it possible to ask it, and subsequently to treat it.

Life changes, new responsibilities and unfamiliar childcare practices accom- 
panied by the transition from pregnancy to maternity leave women isolated, alone and exhausted [27], moreover, becoming a mother is often a joyful but stressful event for many women, and involves a tremendous emotional, physical and social [28], in addition to participating in new development tasks [29]. With the grid, we are in prevention. It is too early to talk about a disorder or pathology, the process of setting up the link is dynamic and multifactorial. The grid tries to evaluate, in addition to what is happening at the present moment, the possibility of a dynamics of the mother-child couple and of its entourage. The tool is not intended to label dyads in difficulty but to define the conditions necessary to offer support, help with first interactions.

\section{Conclusions}

Moreover, our results show the relevance of a clinical use of the scales of early mother-baby interactions on the preventive and therapeutic level in order to remedy any difficulty of installation of a secure link between the dyad.

One could therefore imagine a prevention and follow-up program for each woman to identify at risk during her pregnancy, because even before her birth the child is taken as a family, emotional and psychic organization which makes the link, after the meeting, human and so full of meaning.

\section{Conflicts of Interest}

The authors declare no conflicts of interest regarding the publication of this paper.

\section{References}

[1] Nelly, T. (2003) Modalités d'observation et d'evaluation des fonctions psychomotrices aux differents âges de la vie.

[2] Kochanska, G., Aksan, N., Knaack, A. and Rhines, M. (2004) Maternal Parenting and Children's Conscience: Early Security as Moderator. Child Development, 75, 1229-1242. https://doi.org/10.1111/j.1467-8624.2004.00735.x

[3] Burgess, K., Marshall, P., Rubin, K. and Fox, N. (2003) Infant Attachment and Temperament as Predictors of Subsequent Externalizing Problems and Cardiac Physiology. Journal of Child Psychology and Psychiatry, 44, 819-831.

https://doi.org/10.1111/1469-7610.00167

[4] Page, M., Whilhelm, M.S., Gamble, W.C. and Card, N.A. (2010) A Comparison of Maternal Sensitivity and Verbal Stimulation as Unique Predictors of Infant SocialEmotional and Cognitive Development. Infant Behavior and Development, 33, 101-110. https://doi.org/10.1016/j.infbeh.2009.12.001

[5] Bienfait, M., et al. (2017) Traduction française de l'autoquestionnaire MIBS (Mother to Infant Bonding Scale) et validation comme évaluation du lien mère nouveau-né en maternité. Devenir, 29, 233-253.

https://doi.org/10.3917/dev.174.0233

[6] Brown, S., Small, R., Faber, B., Krastev, A. and Davis, P. (2002) Early Postnatal Discharge from Hospital for Healthy Mothers and Term Infants. Cochrane Database of Systematic Reviews, No. 3, CD002958. 
https://doi.org/10.1002/14651858.CD002958

[7] Mazet, P. and Féo, A. (1996) Interactions précoces et recherche. Pour la recherche, 9, 2-6.

[8] Tsuchida, A., et al. (2019) Changes in the Association between Postpartum Depression and Mother-Infant Bonding by Parity: Longitudinal Results from the Japan Environment and Children's Study. Journal of Psychiatric Research, 110, 110-116. https://doi.org/10.1016/j.jpsychires.2018.11.022

[9] Figueiredo, B., Costa, R., Pacheco, A. and Pais, A. (2009) Mother-to-Infant Emotional Involvement at Birth. Maternal and Child Health Journal, 13, 539-549. https://doi.org/10.1007/s10995-008-0312-x

[10] Van Bussel, J.C., Spitz, B. and Demyttenaere, K. (2010) Three Self-Report Questionnaires of the Early Mother-to-Infant Bond: Reliability and Validity of the Dutch Version of the MPAS, PBQ and MIBS. Archives of Women's Mental Health, 13, 373-384. https://doi.org/10.1007/s00737-009-0140-z

[11] Sockol, L.E., Battle, C.L., Howard, M. and Davis, T. (2014) Correlates of Impaired Mother-Infant Bonding in a Partial Hospital Program for Perinatal Women. Archives of Women's Mental Health, 17, 465-469. https://doi.org/10.1007/s00737-014-0419-6

[12] Kitamura, T., Takegata, M., Haruna, M., et al. (2015) The Mother-Infant Bonding Scale: Factor Structure and Psychosocial Correlates of Parental Bonding Disorders in Japan. Journal of Child and Family Studies, 24, 393-401.

https://doi.org/10.1007/s10826-013-9849-4

[13] Ohara, M., Okada, T., Aleksic, B., Morikawa, M., Kubota, C., Nakamura, Y., Shiino, T., Yamauchi, A., Uno, Y., Murase, S., Goto, S., Kanai, A., Masuda, T., Nakatochi, M., Ando, M. and Ozaki, N. (2017) Social Support Helps Protect against Perinatal Bonding Failure and Depression among Mothers: A Prospective Cohort Study. Scientific Reports, 7, Article No. 9546. https://doi.org/10.1038/s41598-017-08768-3

[14] Ohara, M., Nakatochi, M., Okada, T., Aleksic, B., Nakamura, Y., Shiino, T., Yamauchi, A., Kubota, C., Morikawa, M., Murase, S., Goto, S., Kanai, A., Kato, R., Ando, M. and Ozaki, N. (2018) Impact of Perceived Rearing and Social Support on Bonding Failure and Depression among Mothers: A Longitudinal Study of Pregnant Women. Journal of Psychiatric Research, 105, 71-77. https://doi.org/10.1016/j.jpsychires.2018.09.001

[15] Yalcin, S.S., Orun, E., Mutlu, B., Madendag, Y., Sinici, I., Dursun, A., Ozkara, H.A., Ustunyurt, Z., Kutluk, S. and Yurdakok, K. (2010) Why Are They Having Infant Colic? A Nested Case-Control Study. Paediatric and Perinatal Epidemiology, 24, 584-596. https://doi.org/10.1111/j.1365-3016.2010.01150.x

[16] Edhborg, M., Nasreen, H.E. and Kabir, Z.N. (2011) Impact of Postpartum Depressive and Anxiety Symptoms on Mothers' Emotional Tie to Their Infants 2-3 Months Postpartum: A Population-Based Study from Rural Bangladesh. Archives of Women's Mental Health, 14, 307-316. https://doi.org/10.1007/s00737-011-0221-7

[17] Vauclair, J. (2004) Développement du jeune enfant. Belin, Paris.

[18] Taylor, A., Atkins, R., Kumar, R., Adams, D. and Glover, V. (2005) A New Motherto-Infant Bonding Scale: Links with Early Maternal Mood. Archives of Women's Mental Health, 8, 45-51. https://doi.org/10.1007/s00737-005-0074-Z

[19] Bienfait, M. (2008) Peut-on repérer des indicateurs de risque dans la mise en place du lien mère-enfant en maternité? Étude clinique à partir de 104 mères hospitalisées en suites de couches au CHU de Montpellier. Thèse de médecine, Université Montpellier 1 .

[20] Reck, C., Klier, C., Pabst, K., et al. (2006) The German Version of the Postpartum 
Bonding Instrument: Psychometric Properties and Association with Postpartum Depression. Archives of Women's Mental Health, 9, 265-271. https://doi.org/10.1007/s00737-006-0144-X

[21] Brockington, I., Aucamp, H. and Fraser, C. (2006) Severe Disorders of the MotherInfant Relationships: Definitions and Frequency. Archives of Women's Mental Health, 9, 243-251. https://doi.org/10.1007/s00737-006-0133-0

[22] Wittkowski, A., Wieck, A. and Mann, A. (2007) An Evaluation of Two Bonding Questionnaires: A Comparison of the Mother-to-Infant Bonding Scale with the Postpartum Bonding Questionnaire in a Sample of Primiparous Mothers. Archives of Women's Mental Health, 10, 171-175. https://doi.org/10.1007/s00737-007-0191-y

[23] Gooden, W. and Struble, K. (1990) Perceived Parental Behavior and the Social Desirability Response Set. Journal of Youth and Adolescence, 19, 605-613.

https://doi.org/10.1007/BF01537179

[24] Bowlby, J. (1969) Attachement et perte. PUF, le fil rouge, Paris.

[25] O’higgins, M., St James, R.I., Glover, V. and Taylor, A. (2013) Mother-Child Bonding at 1 Year; Associations with Symptoms of Postnatal Depression and Bonding in the First Weeks. Archives of Women's Mental Health, 16, 381-389.

https://doi.org/10.1007/s00737-013-0354-y

[26] Yoshida, K., Yamashita, H., Conroy, S., Marks, M. and Kumar, C. (2012) A Japanese Version of Mother-to-Infant Bonding Scale: Factor Structure, Longitudinal Changes and Links with Maternal Mood during the Early Postnatal Period in Japanese Mothers. Archives of Women's Mental Health, 15, 343-352.

https://doi.org/10.1007/s00737-012-0291-1

[27] Razurel, C., Bruchon-Schweitzer, M., Dupanloup, A., Irion, O. and Epiney, M. (2011) Stressful Events, Social Support and Coping Strategies of Primiparous Women during the Postpartum Period: A Qualitative Study. Midwifery, 27, 237-242. https://doi.org/10.1016/j.midw.2009.06.005

[28] Alhasanat, D., Fry-McComish, J. and Yarandi, H.N. (2017) Risk for Postpartum Depression among Immigrant Arabic Women in the United States: A Feasibility Study. Journal of Midwifery \& Women's Health, 62, 470-476. https://doi.org/10.1111/jmwh.12617

[29] Tapleton, L.R.T., Schetter, C.D., Westling, E., Rini, C., Glynn, L.M., Hobel, C.J. and Sandman, C.A. (2012) Perceived Partner Support in Pregnancy Predicts Lower Maternal and Infant Distress. Journal of Family Psychology, 26, 453.

https://doi.org/10.1037/a0028332 